\title{
Organización de la documentación conventual: ejemplo de Sistema de información para el estudio de las secularizaciones
}

\author{
Organization of conventual documentation: an information system to study secularizations
}

Agustín Vivas Moreno (1) y María Guadalupe Pérez OrTiz (2)

(1) Departamento de Informática, Facultad de Biblioteconomía y Documentación, Universidad de Extremadura (Antiguo Hospital Militar), O6071 Badajoz, avivas@alcazaba.unex.es. (2) Seminario Diocesano de San Antón, Cañada Sancha Brava, s/n, 06010 Badajoz, mgperort@alcazaba.unex.es

\begin{abstract}
Resumen
El presente trabajo tiene dos objetivos: por un lado, establecer un modelo general de organización de la documentación generada por las instituciones conventuales, para lo cual se confeccionará un hipotético cuadro de clasificación documental aplicable al conjunto de los archivos conventuales y se analizará someramente cada uno de sus elementos; y por otro, se establecerán las bases para un Sistema de Información para el estudio de las secularizaciones conventuales, tomando como ejemplo lo ubicado en el Archivo Diocesano de Mérida-Badajoz. Para ello, se establecen las líneas generales del proceso secularizador, y se analiza la documentación que, de diversas procedencias, se conserva en el archivo. Técnicas y procedimientos archivísticos, lenguajes documentales y tecnologías de la información son los recursos metodológicos utilizados. Los resultados son un cuadro de clasificación específico, un tesauro ad hoc y un gestor documental automatizado.
\end{abstract}

Palabras clave: Archivos conventuales. Archivos episcopales. Clasificación documental. Secularizaciones. Sistema de información.

\section{Introducción}

Por medio de este trabajo pretendemos establecer un modelo de organización de la documentación conventual. Para ello, confeccionaremos un hipotético cuadro de clasificación aplicable a estos archivos y analizaremos cada uno de sus elementos constitutivos. Además, durante el desarrollo del mismo estableceremos los cimientos para crear un Sistema de Información que nos permita estudiar las secularizaciones conventuales. Para su ejecución hemos tomado como base la documentación custodiada en el fondo antiguo del Archivo Diocesano de MéridaBadajoz (s. XVI-XIX)

\begin{abstract}
The present article has two aims: on the one hand, we want to establish a general model of conventual organization documentation, for which we will make a hypothetical documentary profile to apply on the conventual archives. On the other hand, we establish the groundings to make a Information System about conventual secularizations. For it, we use the documentation stored in the Archivo Diocesano de MéridaBadajoz. We establish the general lines of the process and we analyze the documentation that, of diverse origins, remains in the archive. Archival techniques and methods, documentary languages and information technology have been the resources used. The results are a specific classification profile, a thesaurus and a database.
\end{abstract}

Keywords: Conventual archives. Episcopal archives. Documentary classification. Secularizations. Information system.

1.1. Los archivos diocesanos: el ejemplo del Archivo Diocesano de Mérida-Badajoz

Escasos son los datos que conocemos de este Archivo, dado que carece de una historia que analice su fundación y desarrollo, la procedencia de sus fondos, las ubicaciones en las que se instaló, así como el personal que estuvo al frente. Tras la consulta de algunos estudios sobre la Diócesis de Badajoz (Aldea Vaquero; Marín Martínez; Vives Gatell, 1972-1987, pp. 170-171; López y López, 2000; Sarmiento Pérez, 2005; Solano de Figueroa y Altamirano, 1929-1932; Suárez de Figueroa, 1976) podemos afirmar que el nacimiento del mismo se sitúa tras el Concilio de Trento (1545-1563), cuyas cláusulas determinaron la obligatoriedad de crear archivos para custodiar los documentos diocesanos. 
Conocemos de la mano del historiador don Alberto González que se situaba en el interior del Palacio Episcopal, el cual se localizaba próximo a la Iglesia de Santa María del Castillo. Su ubicación originaria es desconocida alojándose desde los momentos iniciales, de los que tenemos constancia, en el llamado "Almacén del Rey" que en 1380 fue consolidado como sede episcopal (González Rodríguez, 1999, pp. 189190). El Episcopado se mantuvo allí hasta 1705, fecha en la que el obispo Marín de Rodezno (1681-1706) decidió su traslado a extramuros debido a la explosión de un polvorín cercano. Esta situación hace que el que Obispado sea trasladado a un nuevo edificio situado en la calle que unía el Campo de San Francisco con el de San Juan (Leg. 16, n 400).

Ya en el siglo XIX, la Revolución Francesa fue un hecho de terribles consecuencias para la Iglesia española. El Obispado de Badajoz no se vio libre de continuos ataques y en particular su archivo fue gravemente asaltado. El primer hecho al que haremos referencia, ya en el siglo XX, es a la Guerra Civil Española (1936-1939). Ésta no supuso un motivo de pérdidas documentales importantes, puesto que el mayor deterioro que sufrieron los documentos fue por el caos que se produjo en el intento de salvaguardarlos de posibles hurtos (Aldea Vaquero; Marín Martínez; Vives Gatell, 1972-1987, pp. 262263). En la segunda mitad del siglo XX (19651990) el Archivo sufre cuatro traslados. Transcurrido el tiempo el Obispado adquiere la Casa del Cordón (1995), en la calle Obispo San Juan de Ribera, y traslada allí sus dependencias. Para el archivo se designa la parte sótano de la vivienda (Montes, 2002, p. contrap.). En 2006 el arzobispo don Santiago García Aracil, impulsado por salvaguardar el patrimonio eclesiástico y ponerlo a disposición de cuantos lo puedan requerir, ha llevado a término una actuación de suma relevancia para la historia particular del Archivo, pero a la vez para el beneficio de la cultura en general. Se trata de la unificación de los fondos diocesano y catedralicio en único archivo, el denominado Archivo Eclesiástico de Mérida-Badajoz que fue inaugurado el 13 de septiembre de 2007 en el transcurso del XXIII Congreso Nacional de Archiveros de la Iglesia que se celebró en tierras extremeñas.

\subsection{Los Sistemas de Información}

En la sociedad actual es algo cada vez más común que los investigadores de la historia hagan uso de las nuevas tecnologías como lo marca la sociedad en otros ámbitos. La informática en general propicia al investigador importantes medidas de almacenamiento, difusión y ac- ceso a la documentación histórica. Los Sistemas de Información Histórica pueden ser definidos como "organizaciones humanas -más o menos institucionalizadas- que diseñan, administran y utilizan automatismos informáticos para almacenar, tratar, y recuperar información histórica, representada en un conjunto integrado de bases de datos y programas" (García Marco, 2006, p. 225). Los objetivos de los SIH son en líneas generales los siguientes:

- "Pretenden ser una solución integradora: un interface entre el tratamiento meramente archivístico y el meticuloso análisis del dato histórico que ayude a optimizar el flujo de la información en el campo de las ciencias sociales y humanas" (García Marco, 1995, p. 105). De esta manera, se puede y debe profundizar en la documentación "hasta sobrepasar el nivel del documento -interés prioritario de la Archivística - para alcanzar el dato histórico y su tratamiento" (ibidem), sin por ello prescindir de la organización del documento y de las aportaciones que realizan las Ciencias de la Documentación (Bautier, 1985).

- Aspiran a relacionar el mensaje que portan los documentos y la creación de conocimiento partiendo de datos contenidos en las fuentes con el control y preservación de las unidades de instalación (Vivas Moreno, 2000).

- Procuran actuar de puente entre el contenido informacional de los documentos primarios localizados y las necesidades de información y las representaciones cognitivas de los usuarios. Así, organizan los datos históricos de cara a su análisis cuantitativo y cualitativo y tratan de confeccionar representaciones documentales para la recuperación (Vivas Moreno, 2000).

En palabras de García Marco (2006, p. 227), el objetivo último de los SIH es "facilitar mediante herramientas informáticas, conceptuales y sociales el desarrollo de una comunidad científica "dura" en el ámbito de las ciencias sociales del pasado, por medio de la objetivación, estructuración, normalización y depuración compartida de los datos y conocimientos históricos".

\section{Diseño de un cuadro de clasificación aplicable a archivos conventuales}

\subsection{Cuestiones preliminares}

La palabra clasificar proviene del latín classificare, "ordenar o disponer por clases" (Real Academia, 1984, p. 234). De esta definición podemos entender que las clases deben estar consti- 
tuidas por elementos similares. En Diccionario el Uso del Español se define el concepto clasificación como "acción de dividir un conjunto de cosas en clases" (Moliner, 1988, p. 643), entendiendo como clases aquellos grupos que resultan de repartir los elementos de un conjunto, uniendo los que tienen el mismo valor o unas características comunes. En archivística, la clasificación debe ser comprendida como "la operación intelectual que consiste en el establecimiento de las categorías y grupos que reflejan la estructura orgánica y/o funcional del fondo" (Diccionario Terminología, 1993, p. 25). En definitiva, entenderemos aquí por clasificación la operación consistente en agrupar jerárquicamente los documentos de un fondo mediante clases, desde los más amplios a los más específicos, de acuerdo con los principios de procedencia, según el cual los fondos archivísticos de una misma procedencia no pueden mezclarse con los de otra, y orden original o de respeto a la estructura archivística, según el cual un fondo archivístico debe conservar o recibir una clasificación que corresponda a las estructuras administrativas internas del organismo que lo ha creado.

\subsection{Cuadro de clasificación para archivos conventuales: propuesta de trabajo}

A lo largo de esta investigación hemos llevado a término un acercamiento paulatino a los archivos conventuales y a la documentación en ellos custodiada que no has propiciado las herramientas y el conocimiento preciso para emprender la tarea que nos proponemos en este momento: presentar un cuadro de clasificación de documentos conventuales que pudiera ser aplicado en todos y cada uno de los archivos de conventos que componen la Iglesia católica. Antes de ello debemos asentar ciertas premisas: hemos pretendido el establecimiento de un instrumento descriptivo de carácter simplista que atienda a lo múltiple y heterogéneo de la documentación y de los fondos a los que sirve; en el caso de concentración de archivos conventuales en otros archivos, sirvan de ejemplo diocesanos o catedralicios, el cuadro de organización de la entidad receptora debería incluir, por separado, los cuadros de clasificación de los diferentes conventos allí custodiados, y por último, debemos señalar que sólo se presenta registrada la documentación que el convento genera en su funcionamiento diario. En consecuencia, el cuadro aparece dividido en tres grandes secciones: administración, gobierno y justicia que corresponderían con las grandes funciones características de cualquier convento. Obviamente, existe otra documentación - misales, biblias miniadas, cantorales, hagiografías, diarios, etc.- que no ha sido incluida, en cuanto, desde un sentido estricto es considerado como material librario.

\subsubsection{Cuadro de clasificación para archivos conventuales.}

\begin{tabular}{|c|c|}
\hline 1.00 & Administración \\
\hline 1.01 & Cartularios \\
\hline \multirow[t]{8}{*}{1.01 .01} & $\begin{array}{l}\text { Expedientes y escrituras de adquisición } \\
\text { de bienes }\end{array}$ \\
\hline & Compra \\
\hline & Donaciones \\
\hline & Escritura de patronazgo \\
\hline & $\begin{array}{l}\text { Escrituras de fundaciones de obras pías } \\
\text { y capellanías }\end{array}$ \\
\hline & Imposiciones de censos \\
\hline & Permuta \\
\hline & Testamentos \\
\hline 1.02 & Cilleros \\
\hline 1.02 .01 & Cuentas de alimentación \\
\hline 1.02 .02 & Cuentas de cargo y data \\
\hline 1.02 .03 & Limosnas \\
\hline 1.03 & Fábrica conventual \\
\hline 1.03 .01 & Expedientes de reparaciones \\
\hline 1.03 .02 & Presupuestos \\
\hline 1.04 & Patrimonio temporal \\
\hline \multirow[t]{8}{*}{1.04 .01} & Registros de bienes \\
\hline & $\begin{array}{l}\text { Inventarios de objetos sagrados y de } \\
\text { culto }\end{array}$ \\
\hline & Libros de arrendamientos \\
\hline & Libros de donaciones \\
\hline & Libros de fundaciones pías \\
\hline & Libros de misas testamentarias \\
\hline & Libros de patronazgos \\
\hline & Libros de registro de censos \\
\hline 2.00 & Gobierno \\
\hline 2.01 & Capítulos \\
\hline 2.01 .01 & Constituciones \\
\hline 2.01 .02 & Reglas \\
\hline 2.02 & Entradas conventuales \\
\hline 2.02 .01 & Entradas esporádicas \\
\hline \multirow[t]{3}{*}{2.02 .02} & Entradas permanentes \\
\hline & Educandas \\
\hline & Novicias \\
\hline 2.03 & Libros de becerro \\
\hline 2.03 .01 & Disposiciones emanadas en conventos \\
\hline \multirow[t]{7}{*}{2.03 .02} & $\begin{array}{l}\text { Disposiciones recibidas por los conven- } \\
\text { tos }\end{array}$ \\
\hline & Licencias \\
\hline & Mandatos \\
\hline & Privilegios \\
\hline & Reales decretos \\
\hline & Reales órdenes \\
\hline & Sentencias \\
\hline 2.04 & Noviciado \\
\hline
\end{tabular}




\begin{tabular}{|c|c|}
\hline 2.04 .01 & Expedientes de novicias \\
\hline \multirow[t]{2}{*}{2.05} & Defunciones \\
\hline & Libros de obituorios \\
\hline 2.06 & Patentes \\
\hline \multirow[t]{2}{*}{2.06 .01} & Traslados a la entidad conventual \\
\hline & Expedientes de traslados \\
\hline \multirow[t]{2}{*}{2.06 .02} & Traslados a otros conventos \\
\hline & Expedientes de traslados \\
\hline 2.07 & Tomas de hábito y profesiones \\
\hline 2.07 .01 & Registro de profesiones perpetuas \\
\hline 2.07 .02 & Registro de toma de hábitos \\
\hline 2.08 & Visitas conventuales \\
\hline 2.08 .01 & Registro de visitas a religiosas \\
\hline \multirow[t]{2}{*}{2.08 .02} & $\begin{array}{l}\text { Registro de visitas para celebración de } \\
\text { elecciones }\end{array}$ \\
\hline & Informe del proceso electoral. \\
\hline \multirow[t]{3}{*}{2.08 .03} & Registro de visitas para inspección \\
\hline & Inspección de celdas \\
\hline & Inspección de clausura \\
\hline 3.00 & Justicia \\
\hline 3.01 & Pleitos civiles \\
\hline \multirow[t]{4}{*}{3.01 .01} & Expedientes de pleitos civiles \\
\hline & Herencias \\
\hline & Impagos \\
\hline & Reclamaciones \\
\hline 3.02 & Pleitos criminales \\
\hline \multirow[t]{5}{*}{3.02 .01} & Expedientes de pleitos criminales \\
\hline & Agresiones \\
\hline & Amancebamiento \\
\hline & Deudas \\
\hline & Escándalos \\
\hline
\end{tabular}

\subsubsection{Análisis de series documentales}

Como indicábamos en un apartado anterior, el cuadro de clasificación expuesto recoge exclusivamente la documentación que ha sido generada en el funcionamiento diario de un convento, quedando a margen otros documentos que no corresponden con estas cuestiones. En base a ello, el cuadro de clasificación aparece divido en tres grandes secciones: administración, gobierno y justicia. Procedamos a su análisis:

1.00 Administración: La primera de las secciones que integra este cuadro de clasificación es la destinada a la gestión de los bienes conventuales. Está estructurada documentalmente en cuatro subsecciones:

La primera de ellas es Cartularios (1.01). Se trata de libros en los que los conventos anotaban las operaciones desarrolladas para la gestión de arrendamientos, censos, donaciones, herencias y permutas de bienes, así como las demás escrituras que daban fe de sus pertenencias. Consta de una única serie documental: Expedientes y escrituras de adquisición de bienes (1.01.01), que incluye la documentación surgida en los procesos de adquisición de bienes por parte de las entidades conventuales, así como las escrituras que se generan de estas operaciones. Dichos expedientes corresponden a varios procedimientos:

- Compras: son los documentos que se originan por las adquisiciones de bienes por parte de las entidades conventuales. Estas compras solían dividirse en dos grandes grupos: de alimentación, registraban los gastos empleados en la compra de productos alimentarios no generados por el convento pero necesarios para la comunidad para su subsistencia; y de adquisición de propiedades, aquellas entidades que disponían de economías saneadas solían adquirir terrenos, solares, etc.

- Donaciones: documentos en los que se especifican los bienes cedidos al convento por esta vía. Las donaciones solían ser efectuadas mediante dos procedimientos: inter vivos, que es la que se hace en la cuantía y en las condiciones que exigen las leyes para que tengan efectos en la vida del donante, y mortis causa, la que se hace para ser cumplida después del fallecimiento del donante y se rige por las reglas de condiciones testamentarias (Diccionario, 2000). El objeto de donación solía ser una propiedad, urbana o rústica, o una cuantía en metálico.

- Escritura de patronazgo: documentación en la que se disponen los beneficios que los conventos obtendrán de la mano del llamado patrón. En épocas determinadas los conventos llegaron a elegir a sus patrones en base a lo que estos podían ofrecerles.

- Escritura de fundaciones de obras pías y capellanías: se trata de las actas fundacionales de capellanías y obras pías en los conventos. Según Iguacen Borau (1991, p. 393),

Están formadas por conjuntos de bienes destinados a un fin piadoso por la voluntad del disponente, quien determina si dichos bienes han de constituir un ente autónomo erigido en persona jurídica o si han de incorporarse al patrimonio de alguna persona jurídica pública con la carga duradera de atender al fin piadoso que ha designado su fundador.

- Imposiciones de censos: dentro de la economía agraria de España las tierras estaban gravadas por unas rentas denominadas censos (Artola, 1982; Fernández, 1992; Ferreiro, 1979; García Sanz, 1996). Los censos, que generalmente se pagaban en especie, sirvieron de sustento tanto a la monarquía como a la Iglesia. Refiriéndonos a los conventos, ayudaban a la subsistencia de la comunidad y 
llegaron a ser, una fuente de ingresos de suma relevancia.

- Permuta: se trata de la documentación generada en los procesos en los que los conventos se desprendían de alguna de sus propiedades a cambio de otras más ventajosas. El objeto de permuta es una propiedad exenta, básicamente tierras, viñas y suelos de casa (Rodríguez, 1995, p. 286).

- Testamentos: "disposiciones de última voluntad por la cual el testador ordena lo referente a su persona y bienes para después de su muerte" (Diccionario, 1993, p. 759). El testamento solía contener una designación de bienes, mandas, donativos, con indicación de sus respectivos beneficiarios, los cuales solían ser hijos, parientes, extraños y la Iglesia, que en la mayoría de los casos solía recibir una asignación importante.

La segunda subsección denominada Cilleros o Tumbo (1.02) abarca la documentación económica y contable sobre la despensa del convento y la relativa a la distribución de las limosnas. Se integra de tres series documentales. La primera, Cuentas de alimentación (1.02.01) es documentación relativa a los gastos que las entidades religiosas empleaban en la manutención de su comunidad. En estas cuentas puede ser observada detalladamente la alimentación que predominaba en los conventos. La segunda, Cuentas de cargo y data (1.02.02), consiste en documentación relativa a los gastos e ingresos que se realizan en una entidad conventual. Los conventos registraban diariamente los movimientos económicos que se ocasionaban y que quedan reflejados en los "diarios conventuales". Éstos se han convertido en una interesantísima fuente de datos económicos. $Y$ en tercer lugar, la serie Limosnas (1.02.03) hace referencia a los ingresos que el convento recibe por esta vía y la forma en la que los distribuyen.

La tercera subsección es la denominada Fábrica conventual (1.03). Se trata de la documentación originada de reparaciones, reformas, rehabilitaciones, etc, efectuadas en los conventos, así como los gastos que cada una de ellas supusieron. Se integra de dos series documentales. La primera, Expedientes de reparación (1.03.01), incluye los informes que los conventos debían elaborar exponiendo la reforma que querían llevar a efecto en sus instalaciones. Estos eran enviados al Obispado para obtener la licencia que les permitiera efectuar la obra. La segunda, Presupuestos (1.03.02), consiste en la relación de gastos que conllevaba la reparación conventual. Eran elaborados por peritos y maestros aljarifes.
La cuarta y última subsección es la denominada Patrimonio temporal (1.04). En ella se da cabida la documentación sobre los bienes que constituían el patrimonio conventual. Está integrada por una única serie documental: el Registro de bienes (1.04.01), que son los diversos asientos en los que se da constancia de las posesiones conventuales. Dichos expedientes corresponden a diversos procedimientos:

- Inventario de objetos sagrados y de culto: relación de objetos para el culto de los que el convento es poseedor -cálices, patenas, biblias, etc.

- Libros de arrendamientos: libro en el que quedan registrados los procesos de alquiler de las propiedades conventuales.

- Libros de donaciones: registro de los bienes que han sido cedidos al convento mediante esta vía. En él se especifica el donante siempre y cuando no fuera anónimo, los bienes que dona a la entidad y las condiciones en que lo hace.

- Libros de fundaciones pías: registro de capellanías y obras pías que tienen sede en la entidad conventual.

- Libros de misas testamentarias: registro en el que se especifican las misas que deben celebrarse en el convento porque han sido así acordadas en las cláusulas de un testamento.

- Libros de patronazgos: libro en el que se anotaban los patrones conventuales para tener constancia de los bienes que cedían al convento.

- Libros de registros de censos: libro que da constancia de los censos que el convento mantiene y los beneficios que la entidad obtenía a cambio.

2.00 Gobierno: Esta segunda sección refleja todos y cada uno de los aspectos relacionados con la gestión interna del convento. Se compone de ocho subsecciones:

La primera de ellas es los Capítulos (2.01). Se trata de la documentación generada en el desarrollo de juntas celebradas por los religiosos y clérigos regulares a determinados tiempos, conforme a los Estatutos de sus órdenes, para las elecciones de prelados y otros asuntos de interés (Aldea, 1972, p. 339). Se integra por dos series documentales. La primera, Constituciones (2.01.01), incluye la ley fundamental de cada orden, que define cada una de las ordenanzas y estatutos que se debían cumplimentar en los conventos adscritos a la misma (Aldea, 1972, p. 400). La segunda, Reglas (2.01.02), 
consiste en los preceptos que se deben observar en una orden determinada (Aldea, 1972, 3025). Aunque solían ser muy similares, su estudio nos permitirá conocer las diferencias fundamentales que existían entre órdenes, ramas dentro de una misma orden, o de un modo más acusado entre la vertiente masculina y femenina de la misma.

La segunda subsección se denomina Entradas conventuales (2.02) y abarca la documentación sobre las incorporaciones a clausura de nuevos miembros, así como las entradas esporádicas de otros. Este hecho da lugar a dos series documentales: la primera de ellas, Entradas esporádicas (2.02.01) recoge la documentación relativa a entradas temporales de personas ajenas al convento. En segundo término, Entradas permanentes (2.02.02) incluye documentación relativa a las entradas de miembros que, de un modo u otro, formarán parte de la comunidad conventual. Se integran por documentación emitida en dos procedimientos:

- Educandas: Son expedientes de menores de edad que entran en el convento para ser educadas en el mismo y en un futuro profesar. Hace algunos años era habitual que las familias numerosas que tenían dificultades para mantener a sus hijas o niñas huérfanas las enviaran a los conventos donde recibirían no sólo alimentación sino también formación humana y espiritual.

- Novicias: Se trata de los expedientes de admisión de las novicias conventuales.

La tercera subsección, Libros de becerro (2.03), da cabida a la documentación relativa a privilegios concedidos a un convento. Se incluyen tanto reales como pontificios, que servían de base documental y jurídica para la defensa de los derechos de la entidad, puestos muchas veces en discusión por otras entidades o particulares (Rubio Merino, 1999, p. 136). Se dividen en dos series documentales que dependen del emisor. La primera de ellas, Disposiciones emanadas en conventos (2.03.01) incluye la documentación relativa a los acuerdos que se llevan a término en una clausura. En segundo lugar, Disposiciones recibidas por los conventos (2.03.02) abarca el conjunto de documentos sobre privilegios y mandatos que son enviados al convento para su satisfacción o cumplimiento. Se integran de:

- Licencias: documentación relativa a las resoluciones emitidas desde un órgano superior, generalmente el obispado o el Ministerio de Gracia y Justicia, autorizando la realización de una determinada actividad o tarea.
- Mandatos: documentación relativa a las órdenes que desde una instancia superior se envían al convento para que éste las cumpla.

- Privilegios: documentación en la que constan los privilegios que han sido concedidos a una entidad. Solían ser de dos tipos: reales y pontificios, dependiendo de la autoridad de la que partieran.

- Reales decretos: disposiciones de carácter legislativo que, sin ser sometida al órgano adecuado, se promulgan por el poder ejecutivo, en virtud de alguna excepción circunstancial o permanente, previamente determinada. Aparecen firmadas por el rey.

- Reales órdenes: disposiciones de carácter legislativo que en el régimen constitucional monárquico están firmadas por un ministro en nombre del rey.

- Sentencias: documentación recibida por el convento al concluir un juicio en el que ha sido parte activa. En ella se resuelve finalmente sobre el asunto principal, declarando, condenando o absolviendo.

La cuarta subección se denomina Noviciado (2.04). En ella se da cabida la documentación relativa al proceso de formación que seguían los novicios/as en las entidades conventuales durante el año que duraba su preparación. Se constituye de una única serie documental: Expedientes de novicios/as (2.04.01), integrada por los expedientes personales de los novicios y novicias. En ellos se expone detalladamente el proceso seguido durante su formación y los deseos que les llevan a profesar.

La quinta de ellas es Defunciones (2.05). Se trata de documentación relativa a los fallecimientos que se originaban en la entidad conventual. Estas defunciones eran anotadas en los llamados libros de obituorios.

La sexta subsección, Patentes (2.06), recoge los traslados de religiosos/as de un convento a otro, así como las causas que los generaron. Se compone de dos series documentales. La primera, Traslados a la entidad conventual (2.06.01), incluye la documentación sobre traslados de religiosos procedente de otras clausuras a la entidad receptora. En segundo término, Traslados a otros conventos (2.06.02) abarca los conventos también debían recoger información de los traslados que se realizaban desde su entidad.

La séptima subsección es conocida como Toma de hábitos y profesiones (2.07). En ella se alberga la documentación relativa a toma de hábitos de novicias y profesiones perpetuas efec- 
tuadas en la institución. Integra dos series documentales. La primera de ellas es el Registro de profesiones perpetuas (2.07.01), que incluye los expedientes elaborados para cada novicia que recibe los hábitos definitivos en el convento. En segundo lugar, el Registro de toma de hábitos (2.07.02) abarca los expedientes elaborados para cada una de las novicias que reciben sus primeros votos, convirtiéndose de este modo en parte activad de la institución conventual.

La octava y última subsección es denominada Visitas conventuales (2.08). En ella aparece toda la información generada en las visitas efectuadas a las clausuras. Integra tres series documentales. En primer lugar, el Registro de visitas a religiosos (2.08.01), que, como su nombre indica, es el libro en el que se anotaban las visitas que recibían los religiosos en los locutorios, así como la periodicidad en que eran efectuadas. En segundo término, el Registro de visitas para la celebración de elecciones (2.08.02), que incluye la documentación relativa a las visitas efectuadas por el obispo o uno de sus emisarios a la clausura para la celebración de las elecciones conventuales. Por último, el Registro de visitas para inspección (2.08.03), guarda la documentación generada por las visitas del obispo o sus emisarios a las instalaciones conventuales, con el fin de observar el funcionamiento de las mismas.

3.00 Justicia es la tercera y última sección que integra este cuadro de clasificación diseñado para documentación conventual. En ella se recoge la documentación relacionada con la administración de justicia en las entidades conventuales o con documentación judicial que se genera por la participación de los conventos en procesos judiciales. Dichas tareas dan lugar a dos subsecciones:

La primera de ellas es Pleitos civiles (3.01). Se trata de la documentación relativa a los pleitos que han sido tratados por esta vía. Se compone de una sola serie documental: Expedientes de pleitos civiles (3.01.01), que son los expedientes ocasionados por tres siguientes procedimientos:

- Herencias: Son aquellos pleitos que han sido motivados por problemas de herencias. En los conventos, ésta era otra vía importante de ingresos. Sin embargo, en algunos casos el cumplimiento de una herencia ocasionaba conflictos entre los familiares y el convento que desencadenaban procesos judiciales.

- Impagos: pleitos motivados por la falta del pago de una deuda al término del plazo estipulado para satisfacerla.
- Reclamaciones: Son aquellos pleitos que han sido presentados con el fin de protestar contra algo $\mathrm{u}$ oponerse a ello.

La segunda subsección es denominada Pleitos criminales (3.02). Se trata de la documentación relativa a los pleitos que han sido tratados por esta vía. Se compone de una única serie documental: Expedientes de pleitos criminales (3.02.01), que son generados por dos procedimientos: las Agresiones — pleitos ocasionados por ataques violentos que han causado daño a otra persona-, y las Violaciones de clausura, que son pleitos cuya temática discurre sobre religiosos y religiosas que mantienen contactos sexuales con otras personas fuera o dentro de las instalaciones conventuales.

\section{Bases para la confección del sistema de información}

\subsection{Aproximación histórica \\ al proceso secularizador}

\subsubsection{El concepto}

El término secularización ha sido utilizado a lo largo de los tiempos en multitud de contextos y bajo variados matices que han hecho que corra el riego de extenderse sin límites llegando en algunos casos a quedar vacío o, al menos, sin un contenido realmente significativo. El primer uso histórico del término (1648) entiende por secularización "la sustracción sin licencia eclesiástica por el poder estatal o público al dominio y al uso eclesiástico de haciendas, cosas, territorios o instituciones, para dedicarlos a fines profanos" (Bonhoefferd, 1968). Para la política es "la desvinculación de la jurisdicción eclesiástica y reducción al régimen civil común" (Higueruela del Pino, 1992, pp. 177-178). Es, por tanto, originariamente un concepto político-jurídico. Su transformación en categoría filosófica e histórico-cultural se dio a principios del siglo XIX. Sociológicamente, la secularización "determina en los procesos de modernización una grieta que provoca la indiferencia, la pérdida de fundamento y la inutilidad de la religión" (Pacomio; Mancuso, 1995, p. 888). Por su parte, la Teología interpreta la secularización como "la ausencia de la manifestación de Dios" (Higueruela del Pino, 1992, p. 177). Para la teología católica, la fenomenología de la secularización traza una nueva visión de la relación fe-mundo: "el proceso de secularización guarda relación con la idea bíblica de creación y con la eliminación de aquella división que se ha realizado en Cristo entre lo sagrado y lo profano" (Pacomio; Mancuso, 1995, p. 889). Pero, ¿qué significado tiene la secularización en el entorno conven- 
tual?. Desde este punto de vista la secularización es también "la dispensa concedida a un clérigo para pasar nuevamente al estado secular" (Bernardi; Guarracino, 1997, p. 901). Es, en este orden en el que fundamentaremos nuestro trabajo. Así, secularización es "una autorización dada a un religioso con votos solemnes y por extensión a aquellos con votos simples, para vivir por un tiempo o permanentemente fuera del claustro y su orden, aunque manteniendo la esencia de la profesión religiosa" (Enciclopedia, s.f.).

\subsubsection{El proceso secularizador en España (Si- glos XVIII-XIX): postulados generales.}

El clero del siglo XVIII nada tenía ya que ver con el de épocas pasadas. Hacia 1750 los bienes que la Iglesia había acumulado eran numerosos. Por su parte, el clero regular constituía un estamento aparte que vivía de las rentas extraídas de sus propiedades agrarias. Pero los regulares no contaban con el apoyo episcopal ni del Estado, que junto con la fama de antirregalistas y el convencimiento de sus incapacidades para prestar los servicios que ofrecían los seculares favorecieron la creación de un ambiente negativo (Suárez Fernández, 1983, p. 49). Para mermar sus influencias el poder central atacó sus bienes y los redujo en número.

Nos situamos a finales del siglo XVIII, concretamente en el periodo de reinado de Carlos IV (1788-1808). En este momento se denota en España una carencia de la sensibilidad religiosa. Esta situación tendrá su máximo apogeo en las desamortizaciones que se iniciaron en 1798 (Historia, 1979, pp. 43-50). Esta primera desamortización se realizó a costa de las temporalidades de una orden extinta o de los bienes de instituciones políticamente débiles. Éste pudo ser el logro más importante del reinado de Carlos IV, sin embargo fracasó porque el rey Fernando VII dio contraorden (Artola, 1988-1994, pp. 125-127). En 1806, el Papa Pío VII concedió al rey la facultad de enajenar la séptima parte de los predios pertenecientes a iglesias, monasterios, conventos, comunidades y fundaciones (Martínez de Codes, 1996, pp. 433-445).

José Bonaparte durante su gobierno español (1808-1813) propone una legislación, conocida como "Legislación Josefina", basada en tres pilares: atraer al clero, reducir a los eclesiásticos y suprimir a los regulares. Nos situamos en el reinado de Fernando VII (1808/1814-1833) para tratar de analizar las medidas propuestas en relación a las órdenes. Las Cortes se ocuparon de este problema como un tema de interés, ya que habían sido suprimidas por el Gobierno afrancesado (1809). Por ello, optan por seguir una vía intermedia, es decir, se produce un restablecimiento de las órdenes pero decretando su reducción (Martí Gilabert, 1994, pp. 50-52). El 8 de marzo de 1813 se crea la Regencia, la cual se basó en la estrecha alianza del Trono y el Altar. Durante los primeros años esos favores se traducen en disposiciones que vuelven a poner en vigor las instituciones eclesiásticas, aunque nunca las órdenes religiosas lograron recuperar su esplendor (Artola, 2005, p. 502).

Llegamos al Trienio Liberal (1820-1823), cuyo periodo de desarrollo puede ser definido como el de peores consecuencias para las órdenes religiosas. Las primeras Cortes del Trienio (1820-21) comenzaron con la reorganización y el expurgo del clero regular. Aprobaron el decreto de Disolución y reforma absoluta de las órdenes religiosas (1 de octubre de 1820), de tal forma que quedaban totalmente suprimidas las órdenes monacales, los canónigos regulares, los hospitalarios y los freires de las órdenes militares. Las demás órdenes fueron reformadas. Las postrimerías del Antiguo Régimen coincidieron en España con el final del reinado de Fernando VII, y el inicio del de su hija Isabel II, que durante su minoría de edad estuvo bajo las regencias de su madre, María Cristina, (18331840) y del general Espartero (1840-1843). Durante la regencia, los regulares se vieron inmediatamente afectados por la política religiosa de los liberales, que con gran prontitud adoptaron medidas que les afectaban: supresión de monasterios y conventos en los que hubiese escapado algún fraile para unirse a los carlistas, obligación de entrar en quintas a los novicios, suspensión de los jesuitas, etc. Es durante este periodo cuando debemos comenzar a hablar propiamente de las desamortizaciones (Tomás y Valiente, 1971, p. 88-91). La figura de Mendizábal puede ser considerada como una de las más importantes, en cuanto al tema desamortizador se refiere, dado que de su mano nacieron gran cantidad de decretos. Los más relevantes fueron el Real Decreto de 19 de febrero de 1836, por el que se declararon en venta los bienes de las corporaciones religiosas suprimidas y el Real Decreto de 1 y 8 de marzo de 1836, por el que se manda suprimir todos los monasterios, conventos, colegios y demás institutos religiosos (Simón Segura, 1969, p. 81-85).

Durante la regencia de Espartero (1840-1843) mejoraron las relaciones entre España y Roma. Nos situamos en el reinado de Isabel II (18441866), dentro de la primera fase del mismo, la cual es conocida como la Década Moderada (1844-1854), caracterizada por un periodo de tranquilidad política. Durante este tiempo el Gobierno autorizó que ciertos bienes volviesen 
a ser propiedad del clero secular. También se suspendió la venta de los conventos y monasterios. Estos gestos hicieron cambiar la actitud de la Santa Sede, que en 1845 firmó con España un convenio por el que se restablecían las relaciones diplomáticas (Historia, 1979, p. 151-153). Por último, la desamortización de Pascual Madoz (1855) es considerada como la mayor de las desarrolladas hasta la fecha, ya que salvo las interrupciones de 1856 y 1858, llega al siglo XX (Simón Segura, 1969, p. 165-212).

En resumen, podemos señalar que las medidas ejecutadas por el Estado Español desde principios del siglo XVIII -y en particular las que se trazaron durante el Trienio Liberal (1820-23) en relación a las órdenes religiosas - fueron la causa principal y el detonante absoluto que hizo que un considerable número de religiosos de las clausuras españolas solicitaran su secularización.

\subsection{Sistema de Información para el estudio de las secularizaciones conventuales}

Una vez expuestas las características generales que definen la documentación secularizadora y explicado el concepto de Sistema de Información Histórica (SIH) nos centraremos en la forma en la que hemos construido un $\mathrm{SIH}$ para esta documentación.

\subsubsection{Objetivos}

El objetivo primordial de este trabajo era realizar un análisis descriptivo e histórico de la documentación sobre secularizaciones custodiada en el fondo antiguo del Archivo Diocesano de Mérida-Badajoz cuyo fin último sería facilitar a los investigadores, usuarios y al propio archivo el acceso y difusión de la documentación. Para ello debieron acometerse varias tareas:

1. Analizar documental e históricamente las 167 agrupaciones documentales sobre secularizaciones existentes en el archivo, extrayendo sus características más relevantes y acometiendo su posterior interpretación.

2. Realizar instrumentos de descripción archivísticos para facilitar, como señalábamos anteriormente, el fácil acceso a la documentación de todos los interesados.

3. Diseñar un tesauro ad hoc, es decir, una herramienta que permita la búsqueda y recuperación de la información a través de la representación del contenido de los documentos.

4. Recuperación automatizada, por medio de la ejecución de un instrumento que nos lo permita.

\subsubsection{Metodología y resultados}

Los cuatro grandes objetivos expuestos en el apartado anterior se consiguieron gracias a la aplicación de metodologías específicas que dieron unos resultados particulares que a continuación desarrollamos:

1. Técnicas de descripción archivísticas. Se desarrollaron por medio de dos etapas: a) análisis de las unidades de instalación, cuyo fin era realizar un examen de contenido de las diferentes agrupaciones documentales y facilitar su localización dentro del archivo; y b) análisis de las 167 agrupaciones documentales sobre secularizaciones existentes en el Archivo Diocesano de Mérida-Badajoz tanto des sus caracteres externos como internos. El resultado obtenido tras la aplicación de las técnicas de descripción archivísticas han sido las tablas y relaciones de contenido como instrumento de control archivístico y el catálogo como instrumento de información.

2. Uso de los lenguajes documentales tanto en la búsqueda como en la recuperación de la información. Para ello ejecutamos tres etapas: a) examen de los documentos individualizadamente, extrayendo de cada uno de ellos sus contenidos; b) determinar conceptos extraídos de los documentos mediante el análisis intelectual y su posterior transformación en términos de indización; y c) selección de los términos de indización que mejor representen el contenido de los documentos, así como el establecimiento de relaciones jerárquicas, asociativas y de equivalencia. El resultado de la aplicación de los lenguajes documentales a la documentación son los índices de persona, entidad, lugar y materia, así como el tesauro.

3. Aplicación de las tecnologías de la información por medio de tres etapas: a) diseño de la estructura de los datos siguiendo el modelo relacional; b) implementación mediante el diseño de gestión de datos dBASE $\mathrm{V}$; y c) incorporación de herramientas que permiten gestionar y manipular los datos que conforman el catálogo, elegir descriptores del tesauro y navegar por ellos, y realizar búsquedas documentales por medio de descriptores y en texto libre. El resultado es el gestor documental automatizado.

4. En último término se acometió el análisis histórico de la documentación. Para llevar a término este análisis debimos estudiar los documentos desde el punto de mira del investigador interesado en la historia, para ello se acometieron diferentes análisis parciales: 
formal, topográfico, cronológico, de procedencias, idiomático y de contenidos. El resultado de esta última etapa se muestra en las características generales para la documentación secularizadora que exponemos a continuación (Pérez Ortiz, 2007, p. 417-456).

\section{Características generales de la documentación}

\section{Varias son las características:}

1. En el fondo antiguo del Archivo Diocesano de Mérida-Badajoz se conservan un total de 167 agrupaciones documentales sobre secularizaciones. De entre ellas, 11 son de carácter temporal y 147 perpetuo. Además, existen 9 documentos dispositivos que hacen referencia a medidas tomadas por la Iglesia y el Gobierno español entorno al proceso secularizador.

2. Las 167 agrupaciones documentales sobre secularizaciones existentes en el archivo se encuentran almacenadas en una única unidad de instalación: el legajo. En total se han contabilizado 30 distribuidos homogéneamente entre el llamado "Archivo del Obispado" y el del "Priorato de San Marcos de León", que son las dos subdivisiones principales existentes en el fondo antiguo del Archivo Diocesano de Mérida-Badajoz.

3. En lo concerniente al análisis de los documentos por su condición de ser manuscritos o impresos, se da un predominio de documentos manuscritos (91\%). La documentación restante $(9 \%)$ alterna una parte manuscrita y otra impresa.

4. En lo que se refiere a la lengua, se da un predomino de los documentos que alternan la combinación de las lenguas castellana y latina $(87,42 \%)$. Esta distribución coincide con la estructura propia de los expedientes secularizadores, que presentan una parte más amplia en castellano, formada por la petición de secularización, partidas sacramentales, pago de tasas y resolución obispal y otra, destinada al breve pontificio, que otorga la secularización en lengua latina. El 11,97\% lo constituyen las secularizaciones que aparecen enteramente en lengua castellana y el $0,61 \%$ restante corresponde a un único documento que aparece enteramente en latín.

5. En lo referente al análisis cronológico, la documentación se distribuye entre los siglos XVIII y XIX. En este sentido, se caracteriza por un predominio casi absoluto de los documentos fechados en el siglo XIX $(95,2 \%)$ frente a los del XVIII (4,2\%). Al margen, en- contramos un documento sin datar que supone el $0,6 \%$. Según hemos podido observar, la época en la que fueron tramitadas un mayor número de secularizaciones en los conventos de la provincia de Badajoz fue el siglo XIX. Si revisamos el apartado histórico, observamos como comenzábamos la narración de los mismos a principios del siglo XVIII, indicando que en fechas anteriores este proceso no tuvo apenas repercusión en la conventualidad española, y señalando que fue el siglo XIX el de mayor trascendencia.

6. En lo que respecta al análisis topográfico, el $72 \%$ de la documentación sobre secularizaciones conventuales refieren en su data tópica poblaciones que hasta finales del siglo XIX pertenecieron a la jurisdicción eclesiástica del Obispado de Badajoz. De dicha cifra, destaca sobremanera Badajoz, por situarse en ella la sede Episcopal. Además, un 23\% lo representan aquellos documentos que reflejan en su topografía lugares que pertenecieron hasta el 1873 al Priorato de San Marcos de León. De entre estas poblaciones destacaremos la ciudad de Llerena, cabecera del Priorato, por ser la que mayor volumen documental aporta. Por ultimo, el 5\% restante se constituye de documentos que reflejan en su data tópica las ciudades de Madrid y Roma (documentación dispositiva).

7. Homogéneas las procedencias documentales, siendo, como el lógico, mayoritariamente conventual con 158 agrupaciones documentales de las 167 existentes. En relación a la procedencia conventual, cabe decir que predomina de forma mayoritaria la franciscana tanto en su rama masculina como femenina (111 documentos), seguida muy de lejos de la agustina (20 documentos), dominica (15 documentos), trinitaria (11 documentos) y jerónima (1 documento). En lo que respecta a las procedencias no conventuales, aparecerán divididas entre la Nunciatura Apostólica y el Ministerio de Gracia y Justicia.

8. Por lo que respecta al contenido, las secularizaciones nos permiten observar además de los datos personales de la religiosa o religioso que los solicita otras cuestiones: En primer lugar, la procedencia, es decir, la orden religiosa y el convento del que han partido un mayor número de secularizaciones. En la rama masculina el convento dominico de Badajoz con 15 y en la femenina el franciscano de Nuestra Señora de las Mercedes de Badajoz con 16 son los que mayor número han tramitado. En segundo término, las causas que motivan estas secularizaciones. Tras el análisis documental podemos señalar 
que son las cargas de conciencia y la asistencia a familiares enfermos las que en han ocasionado un mayor número de secularizaciones en los conventos extremeños, siempre según la documentación custodiada en el Archivo.

\section{Conclusiones}

Tras la exposición de algunos resultados que se extrajeron de esta investigación era menester exponer brevemente algunas de las principales conclusiones de carácter metodológico alcanzadas.

1. La utilidad de la aplicación de lenguajes de indización documental y tesauros a instrumentos de información archivísticos; esto es, la consideración de la Archivística entre las Ciencias de la Documentación, sin rechazar por ello las importantes peculiaridades propias del campo archivístico.

2. El uso de la tecnología de la información es apropiado para que se consuma el proceso informativo documental, es decir, se produzcan las fases de difusión y recepción de la información.

\section{Referencias}

Aldea Vaquero, Q.; Marín Martínez, T.; Vives Gatell, J. (1972). Diccionario de historia eclesiástica. Madrid: Instituto Enrique Florez. CSIC, 1972.

Artola, M. (1982). La Hacienda del Antiguo Régimen. Madrid: Alianza Editorial, 1982.

Artola, M. (1988-1994). Historia de España. III. El Antiguo Régimen: Los Reyes Católicos y los Austrias. Madrid: Alianza Editorial, 1988-1994.

Artola, M. (2005). La España de Fernando VII. Barcelona: RBA, 2005.

Bautier, R. H. (1985). La función de los archivos: la misión de los archivos y las tareas de los archivos... París: UNESCO, 1985

Bernardi, A.; Guarracino, S. (1997). Diccionario de Historia. Vol. II. Barcelona: Anaya y Mario Muchnik, 1997.

Bonhoeffer, D. (1968). Iglesia y mundo. Resistencia y sumisión. Barcelona: Ariel, 1968

Diccionario Terminología Archivística. Madrid: Dirección de Archivos Estatales, 1993.

Diccionario Enciclopédico Ilustrado. Barcelona: Océano, 2000.

Enciclopedia Católica. http://www.enciclopediacatolica. com/s/secularizacion.htm

Fernández, E. (1992). Del censo a la obligación: Historia Agraria de la España Contemporánea. Barcelona: Labor, 1992.

Ferreiro. (1979). Fuentes para el estudio de las formas de crédito popular en el Antiguo Régimen: ventas de renta y ventas de censos. Santiago de Compostela, 1979. // I Jornadas de Metodología aplicada de las ciencias históricas, 1979

García Marco. F. J. (2006). Los Sistemas de Información Histórica: una nueva frontera en la construcción científi- ca de la historia. // Aragón en la Edad Media. 19 (2006) 213-234.

García Marco, J. Los sistemas de información histórica: Entre la Archivística y la Historia. // Ruiz Rodríguez, A. A. (Ed.). Manual de Archivística. Madrid: Síntesis, 1995. p. 105.

García Sanz, A. (1996). El sector agrario durante el siglo XVII: depresión y reajustes. XXIII Historia de España de Menéndez Pidal. Madrid: Espasa-Calpe, 1996.

González Rodríguez, A. (1999). Historia de Badajoz. Badajoz, 1999.

Higueruela del Pino, L. (1992). La secularización como fenómeno histórico. // Cuadernos de Historia Contemporánea de la Universidad Complutense. 14 (1992) 177178.

Historia de la Iglesia en España. Ricardo García Villoslada (dir). Madrid: Biblioteca de Autores Cristianos, 1979.

Iguacen Borau, D (1993): Diccionario del Patrimonio Cultural de la Iglesia. Madrid: Encuentro, 1993.

López y López, T. (2000). La diócesis de Badajoz: Historia ya conclusa. Separatas del boletín de la Real Academia de Extremadura de las Letras y las Artes 5 (2000).

Martí Gilabert, F. (1994). Iglesia y estado en el reinado de Fernando VII. Pamplona: Eunsa, 1994.

Martínez de Codes, R.M. (1996). El proceso desamortizador en la historiografía española. // Actas del XI Congreso Internacional de AHILA. Livepool, 1996.

Moliner, M. (1988). Diccionario del uso del español. Madrid: Gredos, 1988.

Montes, J. J. (2002). Entrevista con don Eladio Méndez Venegas, Archivero Diocesano. // Revista Iglesia en Camino. 459 (2002).

Pacomio, L.; Mancuso, V. (1995). Diccionario teológico enciclopédico español. Navarra: Verbo Divino, 1995.

Pérez Ortiz, Ma Guadalupe. Secularizaciones en conventos de la provincia de Badajoz según la documentación custodiada en el Archivo Diocesano de Mérida-Badajoz (siglos XVI-XIX). // Pax et Emerita: revista de teología y humanidades de la Archidiócesis de Mérida-Badajoz. 2 (2006) 417-456.

Real Academia Española. (1984). Diccionario de la Lengua Española. Madrid: Espasa-Calpe, 1984.

Rodríguez, N. (1995). Fondos monásticos del Archivo Histórico Nacional. Memoria Eclesiae VI (1995) 49-78.

Rubio Merino, P. (1999). Archivística eclesiástica: nociones básicas. Sevilla: E. Guadalquivir, 1999.

Sarmiento Pérez, J. (2005). Reforma beneficial en la Diócesis de Badajoz durante la crisis del Antiguo Régimen (1769-1841). Badajoz: Diputación Provincial, 2005.

Simón Segura, F. (1969). La desamortización española en el siglo XIX. Madrid: Ministerio de Hacienda, 1969.

Solano de Figueroa y Altamirano, J. (1929-1932). Historia eclesiástica de la ciudad y obispado de Badajoz. Badajoz, 1929-1932.

Solar y Taboada, A. (1945). Historia eclesiástica de la ciudad y obispado de Badajoz, continuación de la escrita por Juan Solano de Figueroa. Badajoz, 1945.

Suárez de Figueroa, D. (1976). Historia de la Ciudad de Badajoz. Badajoz, 1976.

Suárez Fernández, L. (1983). Historia general de España y América. Tomo X. La España de las reformas. Hasta el final del reinado de Carlos IV. Madrid: Rialp, 1983.

Tomás y Valiente, F. (1971). El marco político de la desamortización en España. Barcelona: Ariel, 1971.

Vivas Moreno, A. (2000). Sistemas de Información Histórica para las colecciones facticias de archivos históricos: 
modelo investigación. // Cuadernos de documentación multimedia. 10 (2000). 